\title{
Signature capture of red soil patches and their acidity-A case study of Banka district, Bihar, India
}

\author{
Binod K. Vimal, Rajkishore Kumar ${ }^{*}$, C. D. Choudhary, Sunil Kumar, Rakesh Kumar, \\ Y. K. Singh and Ragini kumari
}

Department of Soil Science and Agricultural Chemistry, Bihar Agricultural College, Sabour-813210, Bhagalpur, Bihar, INDIA

${ }^{*}$ Corresponding author. E-mail: kishoreraj1333@gmail.com

Received: August 22, 2015; Revised received: March 1, 2016; Accepted: May 27, 2016

\begin{abstract}
Colour in soils as well as other object is the visual perceptual property which is perceived by human eye. They are governed by spectrum of light corresponding to wavelength or reflected energy of the material. Developed model for soil acidity is based on visual interpretation, principal component and spectral enhancement techniques by using of the satellite image (IRS LISS III, 2014). In this context, red soil patch is much sensitive in red spectral band comparison to green and blue spectral bands and perceived as red tone by human eyes but same soil patch appears green in false colour composite (FCC) image of NIR $(0.70-0.80 \mu \mathrm{m})$, Red $(0.60-0.70 \mu \mathrm{m})$ and Green $(0.50-0.60 \mu \mathrm{m})$ bands. The maximum coverage of red soil patches having low $\mathrm{pH}<6.5(1: 2.5)$ was recognized in 44.07 per cent of the total geographical area (3019.56 sq.km) under Banka district. Maximum red soil patches having their acidity were recognised in Katoria $(18.56 \%)$, Chanan $(15.15 \%)$, Bounsi $(10.44 \%)$ and Banka $(9.92 \%)$ blocks. Overall results indicated that variation of tone in different bands helps for the separation of red soil patches.
\end{abstract}

Keywords: NIR band, RS-GIS, Satellite image, Spectral signature

\section{INTRODUCTION}

The soils are valuable natural resources which are directly or indirectly associated with agricultural activities. Acidity or alkalinity in soils, affect towards nutrient supply in the plant. If a soil is too sour or too sweet, plants cannot take up nutrients like nitrogen $(\mathrm{N})$, phosphorus $(\mathrm{P})$ and potassium $(\mathrm{K})$ (Buckman et. al., 2002). There are four factors that influence signature of soil viz. mineral composition, organic matter, soil moisture and texture (Ben-Dor 2002). Generally, red soils appear near hilly terrain with the presence of iron oxide and they have peculiar tone from surrounding. Wide range of soil colour; gray, black, white, red, brown and yellow is influenced by the content of organic matter, presence of water and oxidation state of iron and magnesium. Iron oxides, clay minerals and soil colour can be measured directly from the spectra (Viscarra Rossel et al., 2009). When light hits objects i.e. soil, water, vegetation some of the wavelengths are absorbed and some are reflected, depending on the materials characteristics (Panda, 2009). In this context, reflected energy from different materials in the terms of different spectral wavelengths is received by satellite sensors and converted into pictorial view. In continuation of sensor based technology, remote sensing and Geographic Information System (GIS) techniques are widely accepted as most reliable, rapid and cost effective for collection of data on status of natural re- sources over large areas (Saxena et al., 2000). Remote sensing data have been used for soil classification, soil resources mapping (Ray et al. 2002, 2004), soil moisture assessment (Engman and Chuhan 1995) and soil degradation (salinity) and mapping (Metternicht et. al. 2003). Examples of some factors that most commonly affect the soils and soil properties $(s)$ as described by V.V. Dokuchaev in Russia and others such as by $\mathrm{H}$. Jenny in the U.S. are climate $(c l)$, organisms $(o)$, topography $(r)$, parent material $(p)$ and time $(t)$ (Jenny 1941). Integrating these factors to express the dynamic nature of soil formation has been shown in the following equation provided by Hans Jenny. $S=f(c l, b, r, p$, $\mathrm{t})$. This equation puts forth the idea that for any specific soil property within a soil such as $\mathrm{pH}$ and clay content etc.(Bricklemyer et. al. 2010) that property is a function of soil forming factors, each being independent but working in unison to form unique soils in Banka district.Soil survey towards land use planning is an important part for the sustainability of agriculture practices. Soil resource inventory provides adequate information in terms of land form, natural vegetation as well as characteristics of soils which can be utilized for land resources management and development (Manchanda et. al., 2002). However, yellow or red soil indicates the presence of iron oxides and their colour associations are influenced by reflected or absorbed energy. Results showed a good correlation between the spectral reflectance from field measurements and 
the spectral reflectance obtained from analyzing the satellite imagery (Hussien et. al. 2014). Therefore, spectral variation over red soils provides an opportunity for the separation from surroundings. Signature capture of perfect tone or spectral responses of the target from satellite image is a researchable issue in RS -GIS domain. Keeping in view and to short out the problem, the present study was carried out for the spectral signature capture of red soil patches corresponding to soil $\mathrm{pH}$ under Banka district of Bihar.

\section{MATERIALS AND METHODS}

Study area: Banka district of Bihar, India was selected for the signature capture of red soil patches (Fig.1). It is situated in far south east of the State Bihar having geographical extension of $24^{0} 30^{\prime}$ to $25^{\circ} 6^{\prime} \mathrm{N}$ and $86^{\circ} 30^{\prime} \mathrm{E}$ to $87^{\circ} 07^{\prime} \mathrm{E}$. The eastern and southern border of the district coincides with district Godda of the state Jharkhand. In west and north east it touches Jamui and Munger district, respectively. The old district Bhagalpur is situated in the north side of Banka. The geographical area of the district is $3019.3465 \mathrm{~km}^{2}$ having eleven blocks. Field survey was done during the month of February, 2014 and eight locations under red soil patches were selected with GPS reading for visual interpretation and image enhancement of the satellite image. Soil $\mathrm{pH}$ was analyzed as per the standard procedure by Jackson (1973) in the laboratory for the availability of acidity level in red soils.

Principal component analysis (PCA): The principal components process the spectral bands to derive a reduced number of parameters (dimensional reduction) and increase interpretability. Generally, processed maps are derived from a statistical analysis of the input rasters which is processes under principal component. In principal component (PC) analysis, one can use the standard or selective analysis, the difference being that in the former, while in the later, only certain bands are chosen (Crosta and Moore, 1989).The principal components that contain spectral information about specific materials, as well as the contribution of individual original bands in relation to the spectral response of the materials of interest. Spectral Feature Fitting to create a similarity score to compare to all other soil samples within the spectral library (Spatial Analyst, http:/geol.hu/ data/online 2012). Principal Component Analysis (PCA) under spectral enhancement was done for the separation of red soil patches from surroundings. To achieve this target, IRS LISS III satellite image (spatial resolution $23.5 \mathrm{~m} \mathrm{x} 23.5 \mathrm{~m}$ ) during the month of March, 2014 and TNT mips (licensed version spatial related software) were used. Ground truth towards red soil patches under PCA analyzed image in different locations was done using GPS and toposheets. Statistical analysis was performed to optimize the number of spectral bands and spectral parameter to be used for estimating soil nutrient content for the unknown pixels of the image (Ghosh et. al., 2012). Details of methodology towards visual interpretation and spectral enhancement processes are being summarised in given flow chart.

\section{RESULTS AND DISCUSSION}

Healthy vegetation appears green due to high reflectance of green band comparison to blue and red bands
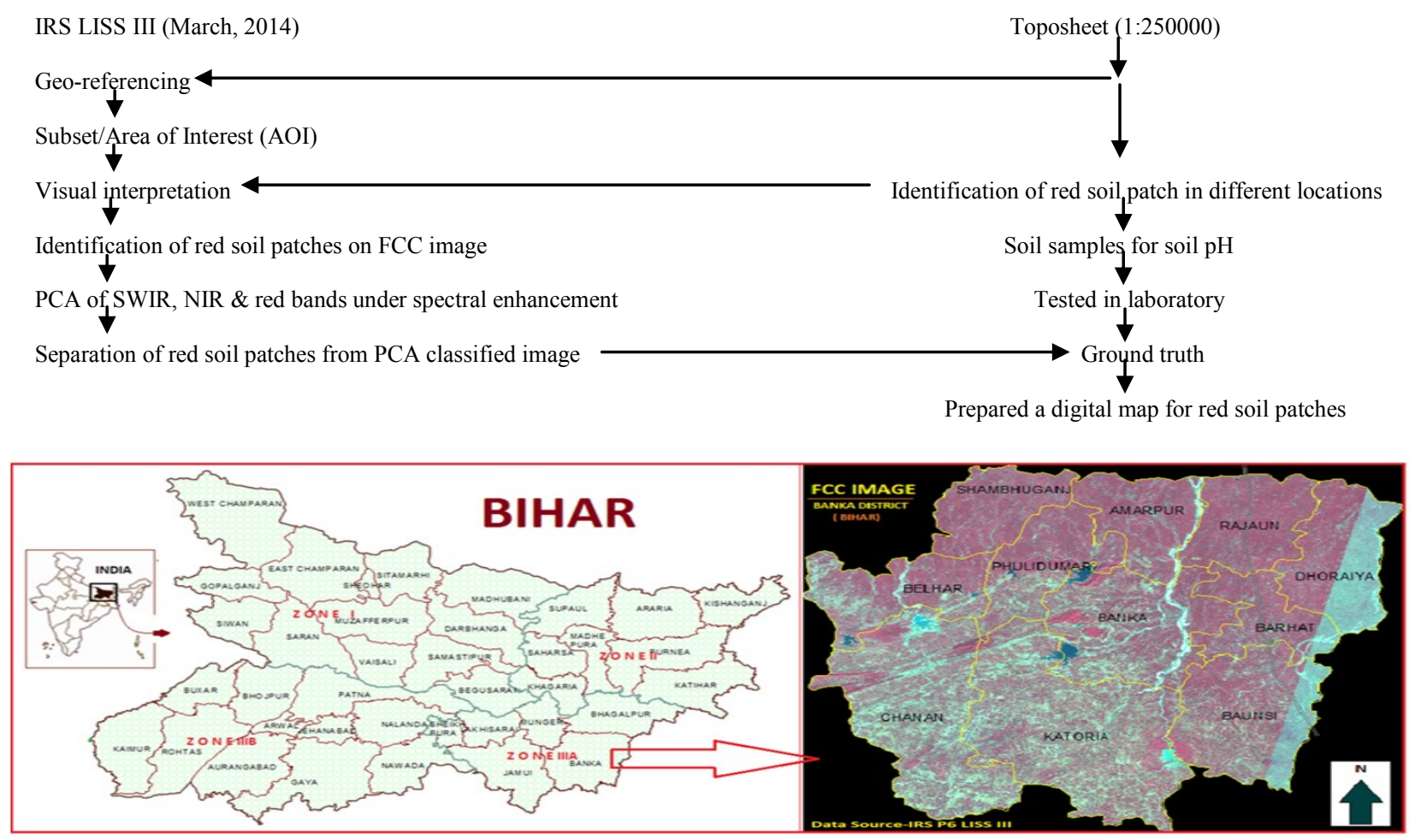

Fig. 1. Location map of the study area. 


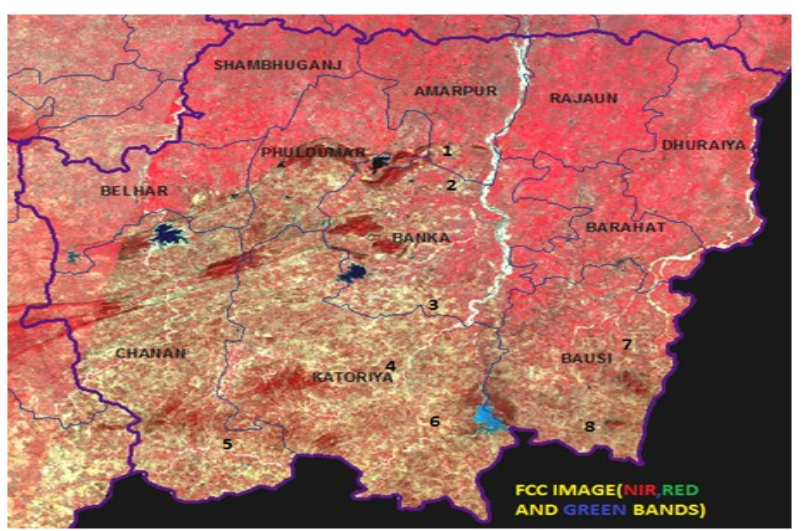

Fig. 2. False Colour Composite image.

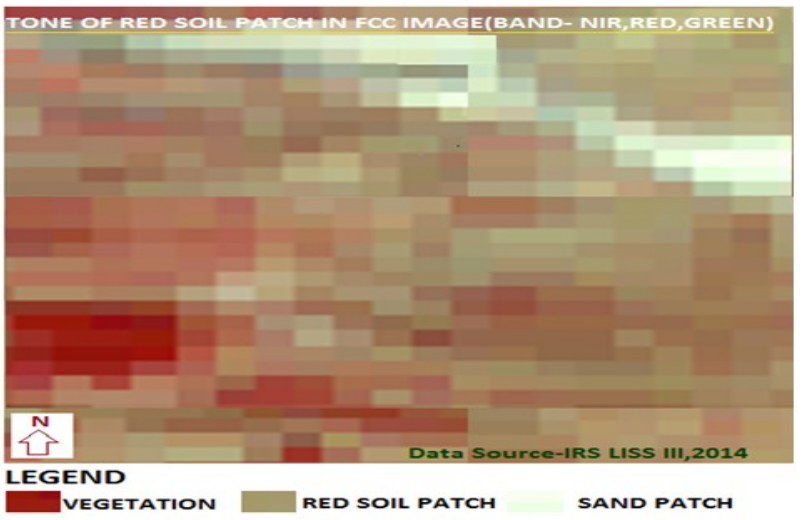

Fig. 3. Red soil patch in green tone.

Table 1. GPS based locations surveyed for spectral signature towards validation of red soil patches and soil $\mathrm{pH}$ (1:2.5), (Locations are plotted in serial number on FCC image, Fig. 2).

\begin{tabular}{llll}
\hline S.N. & Latitude & Longitude & Soil $\mathrm{pH}(1: 2.5)$ \\
\hline 1 & $24^{0} 57^{\prime} 42^{\prime \prime} \mathrm{N}$ & $86^{0} 53^{\prime} 25^{\prime} \mathrm{E}$ & 5.72 \\
2 & $24^{0} 55^{\prime} 00^{\prime} \mathrm{N}$ & $86^{0} 53^{\prime} 45^{\prime}, \mathrm{E}$ & 5.91 \\
3 & $24^{0} 47^{\prime} 33^{\prime \prime} \mathrm{N}$ & $86^{0} 52^{\prime} 46^{\prime \prime} \mathrm{E}$ & 5.66 \\
4 & $24^{0} 42^{\prime} 48^{\prime \prime} \mathrm{N}$ & $86^{0} 50^{\prime} 00^{\prime} \mathrm{E}$ & 5.83 \\
5 & $24^{0} 31^{\prime} 50^{\prime \prime} \mathrm{N}$ & $86^{0} 26^{\prime} 28^{\prime \prime} \mathrm{E}$ & 5.73 \\
6 & $24^{0} 39^{\prime} 27^{\prime} \mathrm{N}$ & $86^{0} 52^{\prime} 10^{\prime \prime} \mathrm{E}$ & 5.71 \\
7 & $24^{0} 44^{\prime} 59^{\prime \prime} \mathrm{N}$ & $87^{0} 2^{\prime} 33^{\prime \prime} \mathrm{E}$ & 5.85 \\
8 & $24^{0} 38^{\prime} 57^{\prime} \mathrm{N}$ & $87^{0} 00^{\prime} 41^{\prime \prime} \mathrm{E}$ & 5.55 \\
\hline
\end{tabular}

Spectral responce of red soil

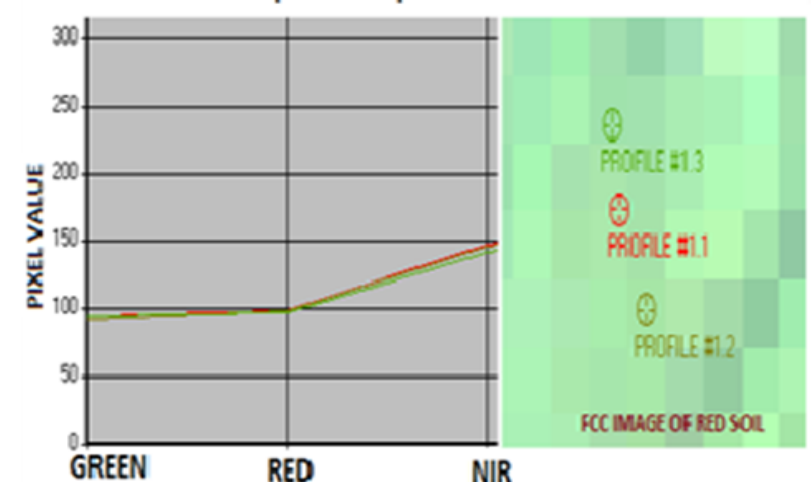

Fig. 4. Spectral response of red soil.

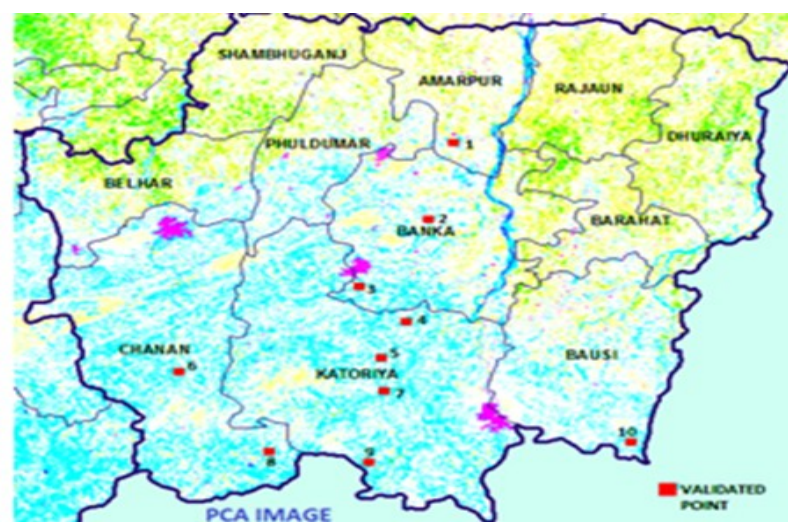

Fig. 5. PCA image of red soil patch.

Table 2. GPS based locations surveyed for spectral signature towards validation of red soil patches and soil $\mathrm{pH}$ (1:2.5), (Locations are plotted in serial number on PCA image, Fig.5).

\begin{tabular}{|c|c|c|c|}
\hline S.N. & Latitude & Longitude & Soil pH $(1: 2.5)$ \\
\hline 1 & $24^{0} 57^{\prime} 58^{\prime \prime} \mathrm{N}$ & $86^{0} 53^{\prime} 12^{\prime \prime} \mathrm{E}$ & 5.81 \\
\hline 2 & $24^{0} 52^{\prime} 46^{\prime \prime} \mathrm{N}$ & $86^{0} 51$ '54', E & 5.76 \\
\hline 3 & $24^{0} 48^{\prime} 20^{\prime \prime} \mathrm{N}$ & $86^{0} 48^{\prime} 32^{\prime \prime} \mathrm{E}$ & 5.64 \\
\hline 4 & $24^{0} 46^{\prime} 00^{\prime \prime} \mathrm{N}$ & $86^{0} 49^{\prime} 14^{\prime \prime} \mathrm{E}$ & 5.83 \\
\hline 5 & $24^{0} 42^{\prime} 26^{\prime \prime} \mathrm{N}$ & $86^{0} 49^{\prime} 14^{\prime \prime} \mathrm{E}$ & 5.81 \\
\hline 6 & $24^{0} 42^{\prime} 26^{\prime \prime} \mathrm{N}$ & $86^{0} 38^{\prime} 12$ '”E & 5.84 \\
\hline 7 & $24^{0} 40^{\prime} 48^{\prime \prime} \mathrm{N}$ & $86^{0} 48{ }^{\prime} 39^{\prime \prime} \mathrm{E}$ & 5.71 \\
\hline 8 & $24^{0} 36^{\prime} 09^{\prime \prime} \mathrm{N}$ & $86^{0} 43^{\prime} 43^{\prime \prime} \mathrm{E}$ & 5.82 \\
\hline 9 & $24^{0} 36^{\prime} 42^{\prime \prime} \mathrm{N}$ & $86^{0} 48^{\prime} 45^{\prime \prime} \mathrm{E}$ & 5.92 \\
\hline 10 & $24^{0} 37^{\prime} 53^{\prime \prime} \mathrm{N}$ & $87^{0} 02{ }^{\prime} 21^{\prime \prime} \mathrm{E}$ & 5.75 \\
\hline
\end{tabular}

Table 3. Total Geographical area, covered with red soil patches in different blocks of Banka district.

\begin{tabular}{llll}
\hline $\begin{array}{l}\text { Different CD blocks under Banka district } \\
\text { of Bihar }\end{array}$ & $\begin{array}{l}\text { Geog. Area } \\
\left(\mathrm{km}^{2}\right)\end{array}$ & $\begin{array}{l}\text { Area under red soil patches } \\
\left(\mathrm{km}^{2}\right)\end{array}$ & $\begin{array}{l}\text { Percentage of red soil } \\
\text { patches }\end{array}$ \\
\hline Sambhuganj & 179.75 & 3.60 & 5.95 \\
Amarpur & 186.25 & 7.45 & 6.17 \\
Rajoun & 197.51 & 5.93 & 6.54 \\
Dhoraiya & 234.14 & 14.05 & 7.75 \\
Barahat & 147.28 & 4.42 & 4.88 \\
Banka & 299.64 & 239.71 & 9.92 \\
Phullidumar & 205.04 & 123.02 & 6.79 \\
Belhar & 236.58 & 123.02 & 7.83 \\
Chanan & 457.47 & 416.30 & 15.15 \\
Katoriya & 560.57 & 521.33 & 18.56 \\
Baunsi & 315.33 & 214.42 & 10.44 \\
Total & 3019.56 & 1673.25 & 100 \\
\hline
\end{tabular}


(Lillesand et. al., 2005) means red objects appear red in same RGB band combination. When light hits the red soils, some wavelengths (energy) are reflected and received by satellite sensors. If the radiation arriving at the sensor is measured at many wavelengths, over a sufficiently broad spectral band, the resulting spectral signature, variation or simply spectrum, can be used to identify the materials in a scene and discriminate among different classes of material (Gary et al., 2003). As per reporting by Lillesand et. al., (2005) healthy vegetation appears red in False Colour Composite image (layers of NIR, red and green bands). It means, red soils or objects are perceived green in same band combination on computer monitor (Fig.3). Spectral response of red soil patches was observed high in NIR and red bands comparison to green (Fig.4). Distinct variations in spectral reflectance show reconciled counter variation in major soil orders across large landscapes. It may be noted that the reflectance characteristics varies across soil types. As expected, darker Vertisols of Karnataka show minimum soil reflectance at all wavelengths compared the lighter Inceptisols of Uttar Pradesh (soils of Agra region) and Aridisols of Rajasthan (soils of Jodhpur region); deep red Alfisols of lateritic origin show intermediate reflectance values. In this regard, the different spectral bands and VIS spectral features generally account for the electronic transitions (ET) associated with the iron-bearing minerals such as hematite and goethite (Viscarra Rossel and Behrens, 2010) is directly auto correlated with red soils patches (Alfisols) of Banka district in Bihar. To identification of those pixels which are associated with green colour corresponding to red soils, GPS reading (latitudes and longitudes) from different locations was taken and plotted on FCC image (Fig.2 and table 1). All locations towards red soils were matched on green pixels (Fig.3). Kadupitiya et. al.(2010) reported that the Hyperion data were used to estimate soil fertility parameters viz., OC, available $\mathrm{N}$, available $\mathrm{P}$ and available $\mathrm{K}$ and soil physical properties such as soil texture, bulk density, particle density, hydraulic conductivity $(K s)$ using DRS (diffuse reflectance Spectroscopy) by pre-processed soil samples and $\mathrm{pH}$ to soil acidity.In continuation of research finding, PCA technique was applied for the separation of green associated pixels using spectral enhancement of NIR, Red and green bands corresponding to $\mathrm{pH}$ variation. $\mathrm{Fe}$ content in red soils patches at Banka district has a significant role in defining the shape of the reflectance spectra due to the $\mathrm{ET}$ of $\mathrm{Fe}^{2+}$ and $\mathrm{Fe}^{3+}$ present in the soils as iron oxides or impurities. The verified spectral reflectance of the soil increases exponentially with the decrease in particle size and the increment was found to be rapid below $0.4 \mathrm{~mm}$. In the quest of red soil patches, spectral reflectance decreases with the increase in particle size and spectral reflectance gave the boost up to validate this model. The similar work has supported by Bowers and Hanks (1965) in respect of reflection of radiant energy from soils. The Principal Component Analysis (PCA) known as a linear transformation technique related to Factor Analysis. It is a set of image bands which is given in as raster input file in software and produces a new set of images, known as components, which are uncorrelated with one another and are ordered in terms of the amount of variance they explain from the original band set. Spatial related softwares viz., TNT mips, Erdas Imagine and Envi provide a platform for the processing of multispectral image (raster) into PCA image. Pixels corresponding to red soils and their purity were enhanced and separated from surrounding which is shown in cyan colour (output image) under PCA classified image. Ground truth was done towards cross checking of assigned red soils on PCA classified image corresponding to the ground using GPS receiver and toposheet. The $\mathrm{pH}$ values of the red soils (tested in the laboratory) were marked in acidic range which were plotted on same cyan colour in PCA classified image even samples of the red soils with latitudes and longitudes position from ten new locations were collected, analyzed and laboratory report of analysed soil samples were cross checked on PCA classified image (Fig.5) and summarized in Table 2. Similar result was found in respect soil $\mathrm{pH}$ and shows the clear cut gap in grey values of colors and the ranges of soil $\mathrm{pH}$ and $\mathrm{pH}$ index values which varies from 7.30 to 7.50 and 0.0070 to 0.0261 , respectively in deep brown color of Nathnager at Bhagalpur district in Bihar (Vinay et. al. 2013). Similar type of work has done in tropical soil characteristics to measuring the of narrow band spectral models (Demattê et. al. 2010) in country level mapping of soils (Viscarra Rossel et. al. 2010) in Australia. Finally, pixels' counting process was applied for the calculation of geographical area having red soil patches under different blocks (Table 3). Results indicated the diversity of possible uses towards red soil properties and their features using remote sensing technique

\section{Conclusion}

This model is based on digital image processing technique under RS-GIS domain in which PCA technique has been applied for the signature capture of red soil patches from surroundings. To achieve this target spectral enhancement process was initiated by using the satellite images IRS LISS III, 2014 under ENVI 5.1spatial related software. PCA image indicated the clear cut demarcation of red soil patches from surrounding. Method of soil spectra collection in digital value was allowed for the conformation of soil spectra, in which specific spectral bands could be associated with soil acidity in respect of soil $\mathrm{pH}$. Based on research finding, maximum coverage of red soil patches having acidity was recognised in Katoria (18.56\%) consequently Chanan (15.15\%), Bounsi (10.44\%) and Banka(9.92\%) blocks. Only1673.25km2 (44.4\%) of 
the total geographical area $(3019.56 \mathrm{~km} 2)$ was traced out under red soil patches which are acidic in nature. Low coverage of red soil patches was traced out in Sambhuganj (5.95\%), Amarpur (6.17\%) and Rajaun (6.54\%) block. Research findings may be helpful for red soil inventory and mapping.

\section{ACKNOWLEDGEMENTS}

First author is thankful to Department of Science and Technology, New Delhi for financial assistance under ongoing research project (SB/EMEQ-173/2013). The Chairman, Department of Soil Science \& Agricultural Chemistry, BAC, Sabour is acknowledged for his valuable suggestions and providing laboratory facilities.

\section{REFERENCES}

Ben-Dor, E. (2002). Quantitative remote sensing of soil properties. Adv. Agron., 2002, 75, 173-243.

Bowers, S. and Hanks, R., (1965). Reflection of radiant energy from soils. Soil Sci., 100, 130-138.

Bricklemyer, R.S.; Brown, D.J. On-the-go visnir (2010). Potential and limitations for mapping soil clay and organic carbon. Comput. Electron. Agric., 70, 209-216.

Buckman, H.O. and Brady, N.C. Weil, R.R. (2002). The nature and properties of soils, $13^{\text {th }}$ Edition. Prentice Hall.

Crosta, A. P., and Moore, J. McM., (1989). Enhancement of Landsat Thematic Mapper imagery for residual soil mapping in SW Minas Gerais State, Brazil: a prospecting case history in Greenstone Belt terrain. Proceedings of the Seventh Thematic Conference on Remote Sensing for Exploration Geology, Calgary, Alberta, Canada, 2- 6 October, 1173-1187.

Demattê, J.A.M., Fiorio, P.R., Araújo, S.R. (2010). Variation of routine soil analysis when compared with hyperspectral narrow band sensing method. Remote Sens., 2010, 2, 1998-2016.

Engman, E.T. and Chauhan, N. (1995). Status of microwave soil moisture measurements with remote sensing. Remote Sensing Environ., 51 (1): 189-198.

Gary A. Shaw and Hsiao-hua K. Burke, (2003). Spectral Imaging for Remote Sensing, Lincon Laboratory Journal Volume 14, Number1.

Ghosh, R., Padmanabhan, N., Patel, K.C. and Siyolkar, R., Soil fertility parameter retrieval and mapping using hyperion data (2012). In Investigations on Hyperspectral Remote Sensing Applications (eds Panigrahy, S. and Manjunath, K.R.), Space Applications Centre (ISRO), Ahmedabad, pp. 29-31.

Hussien, H.M., Karkush, M.O. and Zibbon, A.R.T. (2014).
Studying the effects of contamination on soil properties using remote sensing. Journal of Engineering, 6(20), 78 $-90$

Jackson, M.L. (1973). Soil Chemical Analysis. Prentice- hall of India Pvt. Ltd, New Delhi, pp.40.

Jenny, H. (1941). Factors of Soil Formation a System of Quantitative Pedology; McGraw-Hill Book Company, Inc.: New York, NY, USA.

Kadupitiya, H.K., Sahoo, R.N., Ray, S.S., Chakraborty, D. and Ahmed, N. (2010). Quantitative assessment of soil chemical properties using visible (VIS) and nearinfrared (NIR) proximal hyperspectral data. Trop. Agric., 158: 41-60.

Lillesand, Thomas M., Ralph W. Kiefer, and Jonathan W. Chipman (2005). Remote Sensing and Image Interpretation, Fifth edition. Wiley, New York.

Manchanda, M.L. Kudrat, Mand Tiwari, A.K. (2002). Soil survey and mapping using remote sensing. Tropical Ecology, 43: 61-74.

Metternicht, G.I. and Zinck, J.A. (2003). Remote sensing of soil salinity: potentials and constraints. Remote Sensing Environ., 85 (1): 1-20.

Panda, B.C. (2009). Remote sensing: Principle and application. Viva Books Pvt Ltd.

Ray, S.S., Singh, J.P., Das, G. and Panigrahy, S. (2004). Use of high resolution remote sensing data for generating sitespecific soil management plan. Int. Arch. Photogramm. Remote Sensing Spatial Inf. Syst. B., 35 (7): 127-131.

Ray, S.S., Singh, J.P., Dutta, S. and Panigrahy, S. (2002). Analysis of within field variability of crop and soil using field data and spectral information as a pre-cursor to precision crop management. Int. Arch. Photogramm. Remote Sensing Spatial Inf. Syst. C, 34 (7): 302-307.

Saxena, R.K., Verma , K.S., Chary, G.R., Srivastava, R. and Bartwal, A.K. (2000). IRS-IC data application in watershed characterization and management. International Journal of Remote Sensing, 21, 3197-3208.

Spatial Analyst (2012). Exelis Visual Information Solutions: Boulder, CO, USA, Available online: http://geol.hu/ data/online_help/SpectralAnalyst.html.

Vinay, K., Vimal, B.K., K., Rakesh, K., Rakesh and K., Mukesh, (2013). Determination of soil pH by using digital image processing technique. Journal of Applied and Natural Science, 6 (1): 14-18

Viscarra Rossel RA, Cattle S., Ortega A., Fouad Y. (2009). In situ measurements of soil colour, mineral composition and clay content by vis-NIR spectroscopy. Geoderma $150,253-266$.

Viscarra Rossel, R.A. and Behrens, T. (2010). Using data mining to model and interpret soil diffuse reflectance spectra. Geoderma, 158, 46-54. 